\title{
Efficacy of Intravenous Paracetamol Infusion for Attenuation of Hemodynamic Responses to Laryngoscopy and Tracheal Intubation
}

\author{
Shivani Dalal and Sanjot Ninave* \\ Department of Anaesthesiology, Jawaharlal Nehru Medical College, Datta Meghe \\ Institute of Medical Science, Wardha - 442004, Maharashtra, India; \\ drsusann02@rediffmail.com,shivani1363.sd@gmail.com
}

\begin{abstract}
Background and Aim: Pressor response in relation to laryngoscope and tracheal intubation generally lead to rise in heart rate and blood pressure. This response needs to be controlled. The aim is to study efficacy of intravenous paracetamol infusion given before induction to control hemodynamic response at laryngoscopy and endotracheal intubation. Materials and Methods: It was prospective randomized study, after institution ethical committee clearance, Sixty patients of American society of Anaesthesiology class I and II undergoing elective surgery under general anaesthesia were selected and divided into two groups each comprising 30 patients.Group P received inj. Paracetamol $-20 \mathrm{mg} / \mathrm{kg} 30 \mathrm{~min}$ before induction and Group F received inj. Fentanyl $1 \mathrm{mcg} / \mathrm{kg}$ before induction. The primary objective was to observe hemodynamic response at intubation and 1,3,5,10 min after intubation. The secondary objective was to measure rate pressure product and any side effects associated with drug. Results: There was no demographic difference found between two groups. Both the group showed decreased hemodynamic response, but it was highly significant with inj.fentanyl. Conclusion: IV Paracetamol administration 30 minutes before induction does attenuate hemodynamic response but not as significant as with inj. Fentanyl.
\end{abstract}

Keywords: Endotracheal Intubation, Fentanyl, Laryngoscopy, Paracetamol

\section{Introduction}

Significant hemodynamic changes and unfavourable outcomes are associated with laryngoscopy and tracheal intubation which have hazardous effects on it, lasting for atleast 10 minutes. Sympathetic and adrenal stimulation subsequently leads to catecholamine release and contribute to hemodynamic instability which is tachycardia, hypertension and sometimes life threatening arrhythmias, cerebrovascular accidents and bleeding. This response is due to mechanical stimulation of epipharynx and laryngopharynx and activation of $\alpha$ and $\beta$ adrenergic receptors $\stackrel{1,2}{ }$.
Numerous techniques have been studied for attenuating hemodynamic response including deep plane of anaesthesia and numerous drugs such as beta blockers (esmolol, metaprolol) $)^{3}$, calcium channel blockers (diltiazem), opioids, sodium channel blockers(lignocaine) $)^{4}$, vasodilator (nitroglycerine) $)^{\frac{5}{}}$ and alpha agonists (dexmeditomedine, clonidine).

Among all Opioids, fentanyl is efficacious in at tenuating pressor response to laryngoscopy ${ }^{6}$. Fentanyl is not easily available; also, associated with undesirable complications such as nausea, vomiting, pruritis, sedation and respiratory depression. So there is a need to find a effective alternative which blunt these side effect side effects. There is one 
such drug known-Paracetamol (acetaminophen) whose safety profile is already established ${ }^{\mathrm{Z}}$ and is even safe during pregnancy ${ }^{\circ}$. It categorizes under Aniline Analgesic class of drugs. It is an active metabolite of phenacetin and chemical name is para-acetylaminophenol. Main mechanism of action is inhibition of cyclo-oxygenase enzyme, which is responsible for release of prostaglandins, an important mediator of inflammation, fever and pain. Onset of action is $5-10$ minutes?.

IV preparations has found to be more novel as demonstrated in prospective, randomized, placebocontrolled studies ${ }^{10}$. It is said that apart from its action on COX1 and COX2, it also acts on discrete COX1 splice variant (which was initially thought to be COX3) which is found to be active in central nervous system rather than at the site of injured or inflamed tissue ${ }^{11}$ and has antipyretic effects through hypothalamus. Also it devoid of opioid related side effects. So it is safe, cost effective, easily available and its beneficial effects for pain management and reducing opioids amounts have been establishedamong patients who underwent orthopaedic and gynaecologic surgeries.

Recently, in context of critical illness, it is suggested that IV paracetamol may cause hypotension that is either reduce $\mathrm{SBP}$ or $\mathrm{MAP} \underline{12}-\underline{14}$.

Regarding administration, paracetamol can be administered in three common modes-IV carries a faster time to peak plasma drug concentration (15 minutes after start of infusion), whereas, for oral it requires approximately 2 hours and rectal paracetamol at least 3 hours ${ }^{15}$.

\section{Materials and Methods}

This study was conducted in department of Anaesthesiology Acharya Vinobha Bhave Research Hospital, Jawaharlal Nehru medical College, Sawangi, Wardha over a period of one year from march 2018 to March 2019. Institution ethical committee approval and written informed consent from patients were obtained. After preoperative evaluation, sixty patients with American Society of Anaesthesiology class I and II, undergoing elective surgery under general anaesthesia were selected for this prospective randomized study and those with American Society of Anaesthesiology class III and IV, allergy to paracetamol, addiction with opioids and alcohol, any co-morbities or intake of any drug affecting cardiovascular system were excluded from the study. Group P (Paracetamol group)-20mg/kg and Group F (Fentanyl group)-1 mcg/kg.

In the Induction room, intravenous access was achieved with $18 \mathrm{G} / 20 \mathrm{G}$ cannula, moniter were attached, and baseline vitals were noted for group P inj.Paracetamol was given $20 \mathrm{mg} / \mathrm{kgIV} 30$ minutes before induction. After 30 minutes premedication with inj. Glycopyrrolate $-0.004 \mathrm{mg} / \mathrm{kg}$, inj. Midazolam $-0.05 \mathrm{mg} / \mathrm{kg}$ were given to the patients, which was followed by inj. Fentanyl for group F $1 \mathrm{mcg} / \mathrm{kg}$. Preoxygenated for three minutes using 100\% oxygen by medium concentration mask. Anaesthesia was induced within j. Propofol $-2 \mathrm{mg} / \mathrm{kg}$ till the loss of eye lash reflex and inj.vecuronium $-0.1 \mathrm{mg} / \mathrm{kg}$ was used as anparalyzing agent to facilitate after confirmation of ventilation with Bains circuit. Patients were ventilated for 4 minutes before intubation with 100\% oxygen and endotracheal intubation was done with the appropriate sized ET tube. Intraoperatively patient was maintained on $\mathrm{O} 2 / \mathrm{N} 2 \mathrm{O} / \mathrm{Sevoflurane} / \mathrm{Vecuronium}$ top ups.Following vital parameters HR, MAP, RPP were recorded before induction, at laryngoscopy/intubation and 1,3,5,10mins after intubation. No surgery or any stimulus was allowed till 10 minutes after intubation, which was the end point of study and then depending upon the type of procedure,surgery was allowed to proceed accordingly.

\section{Statistical Analysis}

Data was analysed statistically. Demographic data was analysed using student's $t$ test, variables (hemodynamic parameters) in two groups was compared using chi square test, $\mathrm{p}$ value, student $\mathrm{t}$ test. Software used in the analysis were SPSS 17.0 version, GraphPad Prism 6.0 version and EPI-INFO6.0 version. For the statistical analysis, the level of significance $p<0.05$ which was considered highly significant and $\mathrm{p}<0.0001$ was considered highly significant.

Sample size was calculated by using following formula: $2 \mathrm{SD}^{2}\left(\mathrm{Z}_{\alpha / 2}+\mathrm{Z}_{\beta}\right)$

$\mathrm{d}^{2}$

$\mathrm{d}^{2}$ - magnitude of difference between mean values8.67

Standard Deviation (SD)- Assumed SD based on prior knowledge measured either from pilot study or previous work is $=12^{\frac{19}{}}$

$\mathrm{Z}_{\alpha / 2}$ and $\mathrm{Z}_{\beta}$ are set based on acceptable confidence and power levels generally determined by scientific discipline1.96 and 0.84 respectively. 
Each group contains 30 patients, total sample size of 60 patients,selected patients were randomly allocated into two groups of 30 each using a computer generated randomization table.

\section{Results}

Table 1 shows demographic characteristics [age, gender, body weight, ASAI/II] which were comparable between the 2 group ( $\mathrm{p}>0.05)$.

Table 1. Comparison of patient characteristics in 2 groups

\begin{tabular}{|l|c|c|c|}
\hline \multicolumn{1}{|c|}{ PATIENT } & $\begin{array}{c}\text { GROUP - P } \\
(\mathrm{n}=30)\end{array}$ & $\begin{array}{c}\text { GROUP- } \mathrm{F} \\
(\mathrm{n}=30)\end{array}$ & $\mathrm{p}$ value \\
\hline AGE(years) & $44.03 \pm 4.72$ & $45.75 \pm 3.70$ & $0.12, \mathrm{NS}$ \\
\hline $\begin{array}{l}\text { GENDER } \\
\text { (MALE/ } \\
\text { FEMALE) }\end{array}$ & $31 / 19$ & $28 / 22$ & $0.39, \mathrm{NS}$ \\
\hline $\begin{array}{l}\text { BODY } \\
\text { WEIGHT } \\
(\mathrm{kg})\end{array}$ & $66.66 \pm 6.76$ & $68.27 \pm 6.22$ & $0.34, \mathrm{NS}$ \\
\hline ASA(I/II $)$ & $32 / 18$ & $30 / 20$ & $0.79, \mathrm{NS}$ \\
\hline
\end{tabular}

Table 2 shows Baseline heart rate in two groups were comparable showing $\mathrm{p}=0.5$ which was statistically non significant. Fentanyl group showed sustained attenuation of heart rate which was highly significant till 3 minutes $(\mathrm{p}<0.0001)$, value was statistically significant $(\mathrm{p}<0.05)$ at 5 minutes, paracetamol group HR reduced at intubation $(\mathrm{p}<0.05)$ till 1 minute $(\mathrm{p}<0.0001)$ which was statistically significant but from 3 minute till 10 minute HR started rising and returned to its baseline HR showing results statistically non-significant ( $\mathrm{p}=0.62$ ), for fentanyl at 10 minutes HR returned to its baseline value which was not significant $(p>0.05)$. When comparing both group, results were statistically highly significant $(\mathrm{p}<0.0005)$ at intubation till 5 minute and returned to its baseline at 10 minute serving as statistically non significant $(\mathrm{p}=0.431$, $\mathrm{p}>0.05)$ results.
Table 3 shows Mean SBP is comparable at baseline values results were statistically non significant $(\mathrm{p}=$ 0.4 ), at intubation in fentanyl group results were highly significant till 5 minutes $(\mathrm{p}<0.0001)$ but at 10 minute SBP returned to its baseline value serving it statistically non significant. For group $\mathrm{P}$ there was no much attenuation of SBP at 3 minutes it returned to its baseline value so from intubation till 10 minute not much of change was observed serving results statistically non significant $(\mathrm{p}>$ $0.05)$. When comparing both group from intubation till 5 minute results were statistically significant but at 10 minutes both group allowed SBP to return to its baseline value where the results were statistically non significant. $(\mathrm{p}=0.25, \mathrm{p}>0.05)$.

Table 4 shows there was no statistically significant difference in baseline value of mean MAP in 2 group ( $p$ $=0.4, p>0.05)$. There was significant reduction in MAP from intubation till 10 minutes by fentanyl as compared to paracetamol so the results were statistically highly significant $(\mathrm{p}<0.0001)$. In group $-\mathrm{P}$, fall in MAP was evident only at intubation and 1 minute after it making it statistically significant $(\mathrm{p}=0.0001)$, but from 3 minute to 10 minute MAP started rising and returned to its baseline value which was statistically significant $(p>0.05)$. In group- $\mathrm{F}$, attenuation of MAP was significant at induction till 10 minute and was statistically significant $(\mathrm{p}<0.05)$.

Table 5 shows RPP = heart rate (HR)X Systolic Blood Pressure (SBP) is a measure of stress on cardiac muscle/ myocardial oxygen consumption by heart.

In fentanyl group baseline RPP was 10133.22 which was reduced to 7264.5 as compared to paracetamol which reduced to 7821.1 from 10077 . When comparing two group there was sustained attenuation of RPP in fentanyl group till 10 minutes (7326.86) as compared to paracetamol at 10 minutes (10161.06) which is much less and so the results were statistically significant from intubation till 10 minutes. In group- $P$, values were statistically significant till 3 minute from intubation whereas in group-F results were highly significant showing sustained attenuation of RPP.

\section{Discussion}

When 2 groups are compared of paracetamol and fentanyl for attenuation of pressor response to endotracheal intubation to assess hemodynamic responses. 
Table 2. Comparison of changes in Mean Heart Rate (HR) in different time intervals in2 group

\begin{tabular}{|l|c|c|c|c|c|}
\hline & GROUP-P & $\mathrm{p}$ value & GROUP-F & $\mathrm{p}$ value & P value \\
\hline BASELINE & $83.25 \pm 13.18$ & & $81.6 \pm 10.73$ & & $0.5, \mathrm{NS}$ \\
\hline INTUBATION & $80.02 \pm 7.85$ & $0.031, \mathrm{~S}$ & $70.05 \pm 9.74$ & & $0.0001, \mathrm{~S}$ \\
\cline { 1 - 4 } $1 \mathrm{MIN}$ & $76.82 \pm 7.13$ & $<0.0001, \mathrm{~S}$ & $70.05 \pm 10.45$ & \multirow{2}{*}{$<0.0001, \mathrm{~S}$} & $0.0001, \mathrm{~S}$ \\
\cline { 1 - 5 } $3 \mathrm{MIN}$ & $82.7 \pm 10.18$ & $0.76, \mathrm{NS}$ & $70.7 \pm 8.13$ & & $0.0001, \mathrm{~S}$ \\
\hline $5 \mathrm{MIN}$ & $82.85 \pm 13.03$ & $0.86, \mathrm{NS}$ & $78.3 \pm 7.66$ & $0.025, \mathrm{~S}$ & $0.0001, \mathrm{~S}$ \\
\hline $10 \mathrm{MIN}$ & $84.35 \pm 12.10$ & $0.62, \mathrm{NS}$ & $81.5 \pm 8.10$ & $0.94, \mathrm{NS}$ & $0.341, \mathrm{NS}$ \\
\hline
\end{tabular}

Table 3. Comparison of changes in Mean Systolic blood pressure (SBP) in different timeintervals in 2 group

\begin{tabular}{|l|c|c|c|c|c|}
\hline & GROUP-P & P value & GROUP-F & P value & P value \\
\cline { 1 - 4 } BASELINE & $120.62 \pm 22.41$ & & $124.45 \pm 11.04$ & $0.4, \mathrm{NS}$ \\
\cline { 1 - 4 } INTUBATION & $118.22 \pm 13.14$ & $0.32, \mathrm{NS}$ & $105.22 \pm 11.06$ & $<0.0001, \mathrm{~S}$ & $0.0001, \mathrm{~S}$ \\
\cline { 1 - 4 } $1 \mathrm{MIN}$ & $119.8 \pm 11.07$ & $0.68, \mathrm{NS}$ & $108.75 \pm 10.08$ & $0.0002, \mathrm{~S}$ \\
\cline { 1 - 4 } $3 \mathrm{MIN}$ & $120.32 \pm 11.06$ & $0.88, \mathrm{NS}$ & $108.1 \pm 6.88$ & $0.0001, \mathrm{~S}$ \\
\cline { 1 - 4 } $10 \mathrm{MIN}$ & $120.52 \pm 11.81$ & $0.96, \mathrm{NS}$ & $114.22 \pm 6.24$ & $0.012, \mathrm{~S}$ \\
\cline { 1 - 3 } & $120.05 \pm 18.04$ & $0.86, \mathrm{NS}$ & $124.04 \pm 6.11$ & $0.71, \mathrm{NS}$ & $0.25, \mathrm{NS}$ \\
\hline
\end{tabular}

Table 4. Comparison of changes in Mean Arterial pressure (SBP) in different time intervals in 2 group

\begin{tabular}{|l|c|c|c|c|c|}
\hline & GROUP-P & $\mathrm{p}$ value & GROUP-F & p value & P value \\
\hline BASELINE & $93.06 \pm 9.20$ & & $92.82 \pm 8.25$ & & $0.4, \mathrm{NS}$ \\
\hline INTUBATION & $88.80 \pm 6.03$ & $0.0006, \mathrm{~S}$ & $80.51 \pm 4.76$ & & $0.0001, \mathrm{~S}$ \\
\cline { 1 - 4 } $1 \mathrm{MIN}$ & $96.7 \pm 4.26$ & $0.0001, \mathrm{~S}$ & $81.32 \pm 5.88$ & \multirow{2}{*}{$<0.0001, \mathrm{~S}$} & $0.0001, \mathrm{~S}$ \\
\cline { 1 - 4 } $3 \mathrm{MIN}$ & $91.27 \pm 5.41$ & $0.08, \mathrm{NS}$ & $82.64 \pm 4.84$ & & $0.0001, \mathrm{~S}$ \\
\cline { 1 - 4 } $5 \mathrm{MIN}$ & $92.64 \pm 7.21$ & $0.75, \mathrm{NS}$ & $85.52 \pm 5.25$ & & $0.0001, \mathrm{~S}$ \\
\hline $10 \mathrm{MIN}$ & $93.46 \pm 7.41$ & $0.76 . \mathrm{NS}$ & $88.53 \pm 7.07$ & $0.002, \mathrm{~S}$ & $0.0101, \mathrm{~S}$ \\
\hline
\end{tabular}

Table 5. Comparison of changes in Rate pressure product (RPP) in different time intervals in 2 group

\begin{tabular}{|l|c|c|c|c|c|}
\hline & GROUP-P & $\mathrm{p}$ value & GROUP-F & $\mathrm{p}$ value & $\mathrm{p}$ value \\
\hline BASELINE & $10077 \pm 1585.85$ & & $10133.22 \pm 1705.41$ & & $0.4, \mathrm{NS}$ \\
\hline INTUBATION & $7821.1 \pm 1015.4$ & $<0.0001, \mathrm{~S}$ & $7264.5 \pm 1171.15$ & & $0.05, \mathrm{~S}$ \\
\hline $1 \mathrm{MIN}$ & $9540.82 \pm 1065.87$ & $0.010, \mathrm{~S}$ & $7714.8 \pm 1280.6$ & & $0.0001, \mathrm{~S}$ \\
\hline $3 \mathrm{MIN}$ & $9878.02 \pm 1230.08$ & $0.38, \mathrm{NS}$ & $7560.7 \pm 1082.03$ & \multirow{2}{*}{$<0.0001, \mathrm{~S}$} & $0.0001, \mathrm{~S}$ \\
\cline { 1 - 4 } $5 \mathrm{MIN}$ & $9945.66 \pm 1570.2$ & $0.65, \mathrm{NS}$ & $7813.62 \pm 1051.62$ & & $0.0001, \mathrm{~S}$ \\
\hline $10 \mathrm{MIN}$ & $10161.06 \pm 1483.26$ & $0.75, \mathrm{NS}$ & $8026.86 \pm 1116.85$ & & $0.0001, \mathrm{~S}$ \\
\hline
\end{tabular}


The attenuation of heart rate in group-F was consistent till 5 minutes from intubation ( $70.05 \pm 9.74$ to $78.3 \pm 7.66)$ whereas at $10 \mathrm{~min}$ baseline value $81.5 \pm 8.10$ was achieved, result is statistically non significant at baseline and at 10 minute when compared to paracetamol. Whereas in study by ${ }^{16}$ they have compared fentanyl $(2 \mathrm{mcg} / \mathrm{kg})$ and nalbuphine $(0.2 \mathrm{mg} / \mathrm{kg})$ where there was drop in $\mathrm{HR}$ in both the groups at intubation and started rising postinduction till 10 minutes, a rise from baseline value was noted at 10 minute $85.34 \pm 3.98$ from $82.64 \pm 4.00$ and result was statistically significantamong both group. Which showed that fentanyl is effective in attenuation of response heart rate to intubation when compared to paracetamol.

In group-P (paracetamol) attenuation of $\mathrm{HR}$ was observed at intubation $(80.02 \pm 7.85)$ from baseline and was sustained till 1(76.82 \pm 7.13$), 3(82.7 \pm 10.18)$, 5(82.85 $\pm 13.03)$ minute but at 10 minute $(84.35 \pm 12.10)$ a mild rise from baseline $(83.25 \pm 13.18)$ which was statistically non significant and can be considered to be similar to baseline value. Study by ${ }^{17}$ used IV paracetamol 1 hour before caesarean section undergoing general anaesthesia showed rise in HR at intubation (112.45 \pm 12.95$)$ from baseline $(86.96 \pm 10.14)$ result were statistically significant from baseline. Which concluded that paracetamol does produce reduction in heart rate but its effect is not significant when compared to fentanyl in attenuation of heart rate response to intubation.

In a study by ${ }^{18}$ paracetamol given 15 minutes before induction in patients undergoing caesarean section by general anaesthesia showed rise in HR after intubation $(109.75 \pm 18.70)$ from baseline (104.10 \pm 11.21), attenuation was noted from 1 minute $(105.40 \pm 22.18)$ after intubation till 5 minute $(91.95 \pm 17.04)$ present study was comparable till 1 minute $(76.82 \pm 7.13)$ from intubation $(80.02 \pm 7.85)$, concluded that paracetamol can be used to reduce HR response in place where opioids could not be used.

Ali korad et al ${ }^{19}$ in his study used paracetamol (2 gm) 1 hour before induction compared to lignocaine $(1.5 \mathrm{mg} /$ kg) 2 minutes before induction found that with lignocaine there was increase in HR after intubation and change was statistically significant within 9 minutes after intubation $(\mathrm{p}<0.001)$, with paracetamol HR remained stable after intubation $(p=0.8)$ but showed no effectiveness in preventing acute rise in blood pressure after intubation which was similar to present study where rise in SBP in group-P was noted immediately after intubation (119.8 $\pm 11.07)$ till 10 minute $(120.05 \pm 18.04)$ from baseline $(120.62 \pm 22.41)$ there was no additional rise in SBP but no significant attenuation was noted and was statistically non significant. Whereas in group-F there was reduction of SBP at intubation after 1, 3, 5minute and at 10 minute, values came to baseline. This above mentioned results states that fentanyl is better over paracetamol in reducing or maintaining HR/SBP during intubation.

Mean SBP in group-P showed mild attenuation at intubation (118.22 \pm 13.14) but started rising at1(119.8 \pm 11.07$), 3(120.31 \pm 11.06), 5(120.52 \pm 18.04)$, 10 minute $(120.05 \pm 18.04)$ to reached baselinevalue $(120.62$ $\pm 22.41)$ results were statistically non significant, $\frac{18}{}$ after giving paracetamol found rise in SBP immediately after intubation(110.10 \pm 16.03$)$ but attenuated at 1(106.15 \pm 15.32), 3(100.50 \pm 15.30$)$, 5minute ( $88.40 \pm 14.88)$ - which explains the central mechanism of action of paracetamol ${ }^{17}$ after administering $1 \mathrm{gm}$ of paracetamol IV before 1 hour showed increase in SBP at intubation $(126.59 \pm 8.69)$ from baseline (154.93 \pm 15.92$)$, this states both central and peripheral action of paracetamol but has no much effect on SBP.

Mean Arterial Pressure (MAP) in present study showed variable results in group-P at intubation showed attenuation $(88.80 \pm 6.03)$, maximum rise at 1 minute $(96.7 \pm 4.26)$ after 10 minute of intubation values return to baseline $(93.46 \pm 7.41)$ whereas in group-F showed sustained attenuation in rise in MAP at intubation (80.51 $\pm 4.76)$ till 10 minute $(88.53 \pm 7.07)$ similar study by attenuation of MAP by fentanyl which maintained values to baseline (93.51), at intubation (93.12) post intubation 10 minute (92.66) but showed a decrease in SBP with no change in DBP which stated that fentanyl is better in attenuating rise in MAP in response to endotracheal intubation while comparing to drug paracetamol.

In present study for RPP was reduced by fentanyl, from baseline (10133) till 10 minute (8026.86) after intubation, no rise noted during intubation (7264.5) or after it when compared to group P in which there was immediate rise which was noted after 1(9540.82), 3(9878.02), 5 minute (9845.66) after intubation and at 10 minute (10161.06) mild increase from the baseline value (10077) was noted which was statistically significant. When comparing the two groups at intubation no rise of RPP was noted from the baseline but instead showed reduction in each of them. This observation showsthat fentanyl consistently reduces RPP till 10 minute when compared to paracetamol. Which concluded paracetamol does reduce response at 
intubation which is not consistent but no rise in RPP was noted till study was completed.

\section{Conclusion}

Administration of intravenous paracetamol- $20 \mathrm{~m} / \mathrm{kg}, 30$ minutes before induction hadgood efficacy in controlling hemodynamic changes at the time for endotracheal intubation but not as significant as compared to fentanyl.

Paracetamolcan be used as an alternative where opioids could not be used or any contraindication present for its use.

Paracetamol can be used in combination with other drugs to effectively attenuate hemodynamic response.

\section{References}

1. Barak M, Ziser A, Greenberg A, Lischinsky S, Rosenberg B. Hemodynamic and catecholamine response to tracheal intubation:Direct laryngoscopy compared with fiberoptic intubation. Journal of Clinical Anesthesia. 2003; 15:132. https://doi.org/10.1016/S0952-8180(02)00514-7

2. YildizM,Tavlan A, TuncerS, ReisliR, Yosunkaya A, Otelcioglu $S$, et al. Effect of dexmedetomidine on haemodynamic responses to laryngoscopy and intubation: Perioperative haemodynamics and anaesthetic requirements. Drugs R D. 2006; 7:43-52. https://doi.org/10.2165/00126839200607010-00004 PMid:16620136

3. Devault M, Greifenstein FE and Harris JR. LC. Circulatory responses to endotracheal intubation in light general anaesthesia; the effect of atropine and phentolamine. Ansesthesiology .1960; 21:360-2. https://doi.org/10.1097/00000542-196007000-000 04 PMid:13816278

4. Stoelting RK. Circulating responses to laryngoscopy and intubation with or without prior oropharyngeal viscous lidocaine. Anaesthesia Analgesia. 1977; 56:618-621. https://doi.org/10.1213/00000539-197709000-00004

5. Nielson DJ. The effect of intranasally administered nitroglycerineon thebloodpressureresponsetolaryngoscopy and intubation in patients undergoing coronary artery bypass graft surgery. Acta Anaesthesiologica Scandinavia. 1986; 30:23-7. https://doi.org/10.1111/j.1399-6576.1986. tb02360.x PMid:3083630

6. Black TE, Kay B, Healy TE. Reducing the haemodynamic responses to laryngoscopy and intubation. A comparison of alfentanil with fentanyl. Anaesthesia. 1984; 39:883-7. https://doi.org/10.1111/j.1365-2044.1984.tb06575.x PMid:6443596

7. Lesko SM, Mitchell AA. The safety of acetaminophen and ibuprofen among children younger than two years old. Pediatrics. 1999. p. 104-39. https://doi.org/10.1542/ peds.104.4.e39 PMid:10506264

8. Bertolini A, Ferrari A, Ottani A, Guerzoni S, Tacchi R, Leone S. Paracetamol: New vistas of an old drug. CNS Drug Reviews. 2006; 12:250-75. https://doi.org/10.1111/j.15273458.2006.00250.x PMid:17227290 PMCid:PMC6506194

9. Kashif S, Hamid M. Efficacy of intravenous paracetamol on pressor response in patients undergoing cesarean section under general anesthesia. Journal of Anaesthesiology Clinical Pharmacology. 2016; 32(2):210-3. https://doi. org/10.4103/0970-9185.173332 PMid:27275051 PMCid :PMC4874076

10. Craig M, Jeavons R, Probert J, Benger J. Randomised comparison of intravenous paracetamol and intravenous morphine for acute traumatic limb pain in the emergency department. Emergency Medicine Journal. 2012; 29:37-9. https://doi.org/10.1136/emj.2010.104687 PMid:21362 724

11. Sharma CV, Mehta V. Paracetamol: mechanisms and updates. Continuing Education in Anaesthesia Critical Care and Pain. 2014; 14(4):153-8. https://doi.org/10.1093/ bjaceaccp/mkt049

12. Duncan CN, Seet J, Baker S. Centrally administered parenteral paracetamol: A potentially under-reported cause of haemodynamic instability within the adult intensive care unit. Australian Critical Care. 2012; 25:131-1. https://doi. org/10.1016/j.aucc.2011.12.028

13. Boyle M, Nicholson L, O’Brien M, Flynn G M, Collins D W, Walsh W R. et al. Paracetamol induced skin blood flow and blood pressure changes in febrile intensive care patients: An observational study. Australian Critical Care. 2010; 23:208-14. https://doi.org/10.1016/j.aucc.2010.06.004 PMid:20655241

14. Krajcova A, Matousek V, Duska F. Mechanism of paracetamol-induced hypotension in critically ill patients: a prospective observational cross-over study. Australian Critical Care. 2013; 26:136-41. https://doi.org/10.1016/j. aucc.2012.02.002 PMid:22424816

15. Singla NK, Parulan C, Samson R, Hutchinson J, Bushnell R, Beja EG. Plasma and cerebrospinal fluid pharmacokinetic parameters after single-dose administration of intravenous, oral, or rectal acetaminophen. Pain Practice. 2012; 112:52332. https://doi.org/10.1111/j.1533-2500.2012.00556.x PMid:22524979

16. Ali Kord Valeshabad A, Nabavian O, Nourijelyani K. Attenuation of hemodynamic responses to laryngoscopy and tracheal intubation: Propacetamol versus lidocainea randomized clinicaltrial. AnesthesiologyResearchandPractice. 2014. p. 170247. https://doi.org/10.1155/2014/170247 PMid:24822063 PMCid:PMC4005081 
17. Khanday SB, Mir AH, Sofi KP, Lone AQ, Shah AN. Evaluation and comparison of fentanyl versus nalbuphine for attenuation of hemodynamic response to laryngoscopy and endotracheal intubation in general anesthesia. Anesthesia: Essays and Researches. 2019; 13:111-8. https://doi.org/10.4103/aer. AER_16_19 PMid:31031490 PMCid:PMC6444961

18. Sanum K, Hamid M. Efficacy of intravenous paracetamol on pressor response in patients undergoing cesarean section under general anesthesia. Journal of Anaesthesiology,
Clinical Pharmacology. 2016; 32(2):210. https://doi. org/10.4103/0970-9185.173332 PMid:27275051 PMCid:P MC4874076

19. Ghasem S, Molkizadeh A, Amini S. Effect of intravenous acetaminophen (paracetamol) on hemodynamic parameters following endotracheal tube intubation and postoperative pain in caesarian section surgeries. Anesthesiology and Pain Medicine. 2015; 5(6):30062. https://doi.org/10.5812/ aapm.30062 PMid:26705524 PMCid:PMC4688817 